\title{
Exploring Local Governance and E-Services in Qatar
}

\author{
Nada Abdelkader Benmansour, Qatar University, Doha, Qatar \\ Noora Ahmed Lari, Qatar University, Doha, Qatar \\ Bethany Shockley, American University of Sharjah, Sharjah, UAE
}

\begin{abstract}
Properly implemented, e-government enables improved government efficiency and greater engagement with citizens. The State of Qatar has implemented many e-government initiatives but little has been done to investigate their progress. This study aims to bridge the knowledge gap by shedding the light on a specific e-government initiative: the Baladiya application system, the electronic service for municipalities. It uses qualitative data from semi-structured interviews conducted with the director of customer service in each of the municipalities in Qatar. An inductive approach allowed findings to emerge. E-government provides a broad array of services to local users however three main aspects remain problematic. First, the high quantity but low quality of information received from users via e-government hinders the customer relations. Second, while services are readily available, e-government channels are not widely adopted. Finally, the complex process for service delivery contributes to create a relatively opaque user experience.
\end{abstract}

\section{KEYWORDS}

Efficiency, E-Government, Governance, Local Government, Middle East, Services

\section{INTRODUCTION}

The intended impact of e-government is better government. Properly implemented, it promises better service provision, improved efficiency, and greater engagement with citizens. However, the evidence for these benefits is mixed; it varies both by country and by program (Foley and Alfonso, 2009; Weerakkody et al., 2011). In fact, many countries around the world, including some Arab states, have not been successful in securing these outcomes (Lui and Yuan, 2015; Salem, 2006). Like other wealthy development-minded states in the Arab Gulf, the State of Qatar has implemented a number of e-government initiatives (Al-Kubaisi, 2018). Little is known about the implementation progress and resulting challenges as research on this region, and Qatar in particular, is still in the nascent stage. This study aims to bridge the knowledge gap by conducting a qualitative analysis of the municipal e-government system in order to understand how citizens interact with local government. It focuses on the perspectives and experiences of local government officials who are familiar with the day-today operations of the service provision and customer usage of e-government tools.

\section{DOI: 10.4018/IJPADA.2019100101}

This article, originally published under IGI Global's copyright on October 1, 2019 will proceed with publication as an Open Access article starting on February 4, 2021 in the gold Open Access journal, International Journal of Public Administration in the Digital Age (converted to gold Open Access January 1, 2021), and will be distributed under the terms of the Creative Commons Attribution License (http://creativecommons.org/licenses/by/4.0/) which permits unrestricted use, distribution, and production in any medium, provided the author of the original work and original publication source are properly credited. 
E-government encompasses a broad range of activities, including the use of information and communication technologies (ICTs), to improve the activities of public sector organizations and to provide better public services to citizens and businesses (Ebrahim and Irani, 2005). In addition to increases in service quality and efficiency, it also purports to make government services more accessible and to foster transparency and accountability (Norris and Riddick, 2013; Bolivar et al., 2007). Even though the scholarly research has strongly questioned the unbridled optimism about e-government, countries in the developing world continue to implement these innovations (Norris and Reddick, 2013; Lui and Yuan, 2015).

However, as with any innovative governance tool, the promised gains of e-governance are not achieved automatically but are contingent on the complex realities of the policy design, the implementation, and the local context and to users' adoption of e-government services. In reality, since decisions about government's use of information technologies are often made by top managers in order to serve the organization as a whole, e-government often results in the preservation of the statusquo organizational structure and power dynamics (Kraemer and King, 2006). In the case of Qatar, a highly centralized state, e-government may not necessarily lead to increased decentralization and democratic transparency. Rather, as revealed by the subsequent analysis, the lack of decentralization acts as a barrier to realizing the full potential of e-government since citizens have been somewhat hesitant to adopt digital methods of communication implemented from the top-down.

Still, while e-government is by no means a harbinger of democracy, it may help local governments identify user needs, thereby boosting government efficiency (Norris and Reddick, 2013). In fact, the results show that all interviewees held positive perceptions of the e-government initiative, confirming that it speeds the processing of requests and reduces service delivery time. On the other hand, these benefits are contingent upon users adopting and properly using e-government mechanisms, which is problematic in Qatar. As will be subsequently shown, low adoption is due in part to a lack of clear information for local service users about which office to address complaints and requests. The process of service delivery and citizen feedback is generally opaque, calling for government action to raise awareness of e-government services.

The following research will discuss the relevant literature on e-government adoption and its implications for improved efficiency. It will also review e-government innovations in the case of Qatar. Findings from the interviews are subsequently presented along with analysis and conclusions. In doing so, the paper seeks to answer the following research questions:

R1: What is the impact of e-government innovations on local government service provision in the context of Qatar?

R2: Does e-government contribute to efficient service delivery?

R3: Does e-government enable transparent and participatory governance?

\section{ADOPTING E-GOVERNMENT}

Technology has revolutionized the delivery of government services. The public can now access government sites and apply for services. Meanwhile, public officials receive user requests and verify that they meet the required criteria. While there is a plethora of benefits associated with such a paradigm shift, there is still a need to address potential challenges. Such challenges can undermine public satisfaction with e-government services.

E-government strategy has several objectives that are constant across sectors. The first objective is to make government operations efficient through reducing the time citizens spend seeking government services and delivering simple and secure services. The use of e-government is, therefore, intended to shift the processes of procuring, certifying, exchanging, and sending documents to electronic platforms, which can only be accessed by authorized parties (Al-Shafi and Weerakkody, 2009). 
E-government platforms can also be accessed by many people at a time which means more people can access government services.

Al-Yafi et al. (2016) noted that e-government has various advantages, which include assisting governments in achieving public service efficiency. However, the impact of e-government on service efficiency has not yet been fully evaluated with respect to important actors. Many scholars have adopted a user perspective and have ignored the provider perspective, which can be important in determining the success of government service providers (Al-Yafi et al., 2016). In a systematic review, Weerakkody et al. (2013) addressed the adoption of e-government services across ministries and noted that the speed of delivery, ease of use, control, enjoyment, and reliability were significant determinants of service quality. Notably, avoidance of interaction was not correlated with the willingness to use e-government services (Weerakkody et al., 2013).

Zhou (2001) suggested three constituents of an e-government model: citizens (government-tocitizens), government (government-to-government) and businesses (government-to-businesses). In this study, we mainly focused on the government-to-citizen e-government systems. These systems are expected to facilitate citizens' interaction with government through transactions-such as renewing licenses, certificates, permits, and paying taxes - to make them less time consuming and easier to process (Ezz, 2003). Yet the main issue with e-government is the adoption level by the users (Ghaziri, 2003). E-government will not reach its full potential-and governments will not get all the value out of it - until users choose to engage with government via the new technology. Thus, it is crucial to understand the factors that might influence citizens' adoption of e-government services. The next section discusses the adoption of e-government in Qatar local government from the government perspective.

\section{E-Government in Qatar}

Qatar is one of the pioneering Middle Eastern countries in implementing e-government. Some scholars have even argued that Qatar's earliest versions of e-government were among the most democratic in the region (Chatfield and Alhujran, 2009). There were two waves of e-government initiatives in Qatar. The adoption of Qatar e-government services took place in 2000 and the government's ultimate goal was to eventually make all services available online or accessible via the mobile phone. However, it was not until 2004 that information communication technology (ICT) was integrated into government planning, giving birth to the Supreme Council of Information and Communication Technology, known as IctQatar which subsequently assumed control of all e-government initiatives. In late 2013, H.E. Prime Minister Sheikh Abdullah bin Nasser bin Khalifa Al Thani formed a committee, directed by IctQatar and composed of eight of the largest ministries. The committee was charged with developing and guiding the implementation of a nationwide e-government strategy, including the release of the Baladiya application which was the first to receive large-scale promotion from the government in the form of billboards throughout the country.

The resulting Qatar E-government 2020 strategy has one principal vision: "All individuals and businesses will benefit from connecting online with Qatar's more open and efficient government" (Al-Kubaisi, 2018). Qatar's E-government 2020 strategy has three objectives. The first objective is service improvement by focusing on customers (including the public, government entities, multinational corporates and small-scale businesses). The second objective is to create an efficient system that saves time and maximizes the opportunities for both the government and the users of the government services (Al-Kubaisi, 2018). The third objective is increased government openness in order to enhance the country's economic and political systems. Thus, the government aims not only to enhance efficiency but also to promote government openness and transparency.

There are a limited number of studies about the development efforts and current progress of e-government adoption in Qatar. The most relevant research focusing on Qatar was conducted mainly by Al Shafi and Weerakkody who discussed the challenges in e-government implementation, adoption and diffusion about a decade ago, and notably prior to the government promotion of the 
Baladiya application $(2008,2009$, and 2010). This research demonstrates that although large sums of money have been invested in Arab countries such as Qatar, a number of challenges have slowed the implementation and diffusion of their e-government initiatives (Al-Shafi and Weerakkody, 2010; Sahraoui, 2005). Specifically, the adoption and diffusion of e-government has been slower than the Qatari government expected (Al-Shafi, 2008; Al-Shafi and Weerakkody, 2008). Al-Shafi and Weerakkody (2010) examined the factors influencing citizens' intention to adopt e-government services in Qatar and found main constructs which significantly influence the behavioral intention to use e-government services among which social influence (the degree to which peers influence system use), performance expectancy, gender, age, and experience with the internet.

Rabaa'i (2015) addressed the various factors determining the potential for use and re-use of e-government services. He noted that ease of use, perceived risk, perceived usefulness, trust, compatibility, interpersonal as well as external influence, alongside facilitating conditions, all play a central role in determining whether individuals use e-government services. However, when it comes to the situation in Qatar, Al-Shafi, Weerakkody, and Janssen (2009) noted that effort expectancy, was not related to public satisfaction of the use of e-government services. Thus, the challenges identified by previous research on Qatar have centered on adoption and transparency, and the lack thereof.

However, implementation difficulties also exist. For example, the Ministry of Interior, began to provide a number of digital services, which range from paying traffic violations, to student registrations, and to applying online for permits and visas (Weerakkody et al., 2011). In this process, the Ministry discovered how technological issues can impede service delivery. That being the case, the Qatari administration implemented smart cards, biometrics, and public key infrastructure, which are meant to provide reliable and trusted security infrastructure for the various e-government services offered (Weerakkody et al., 2011).

As the previous discussion shows, e-government has been part of governance strategy for a number of years in Qatar, and the results indicate that the user satisfaction levels have significantly improved (Al-Kubaisi, 2018). Both the central and local governments have implemented a collaborative system in which the nature of services offered has been synchronized to make accessibility easier and more secure (Al-Kubaisi, 2018). However, despite considerable experience with the e-government systems, there is a lack of research on local government service delivery. This paper provides a significant update on the most recent developments in the context of Qatar. It also gives insight into the perspective of local service providers who are in charge of implementing national strategies and dealing with customers on a regular basis, but who have been neglected in the e-government narrative to date.

\section{THE STATE OF QATAR}

Qatar is a peninsula running north into the Persian Gulf with a total land area of approximately $11,437 \mathrm{sq} \mathrm{km}$. It is bounded in the south by Saudi Arabia. Although population is estimated to be around 2,666,938 (Planning and Statistics Authority, 2019), only a minority of the population are legal citizens, while the rest are residents who live or work in Qatar but are non-Qataris. As of 2015, more than 80 percent of the population consists of non-nationals from India, Nepal, Philippines and other Arab countries (De Bel-Air, 2014). The capital, Doha, is also the main port, and had a population of 956,457 according to the 2015 census (Qatar Statistic Authority). Smaller cities include, Al Rayyan (population of 605,712), Al Wakra (population of 299,037), Al Khor (population of 202,031) and Al Shemal (population of 8,794).

From an institutional perspective, the municipalities in Qatar are overseen by the Ministry of Municipality and Environment (MME). The municipality as whole, and specifically the municipal director, reports directly to the Undersecretary of the MME. Each municipality is divided into five sections or departments, including the customer service office, which is in charge of attending the public via the new e-government application as well through telephone lines and face-to-face service counters. Our study focuses on the heads of customer service in each municipality as the individual 
most likely to have reliable information and valuable perspectives on the overall implementation of e-government in their locality. Figure 1 shows the organizational structure according to the current Ministry of Municipality and Environment (MME) website (MME, 2019).

\section{METHODOLOGY}

This section outlines the research method and design, including the sampling procedure, the data analysis and ethical considerations. The study was approved by Qatar University Institutional Review Board.

\section{Research Method: A Qualitative Approach}

This paper uses qualitative data from semi-structured interviews collected by members of research team at [blinded for review]. This method was conducted in order to address the main theoretical question posed by the paper and to provide insights into the participants' views when the government was keen to encourage further developments in the E-services offered by municipalities.

\section{Sampling and Recruitment Strategy}

The State of Qatar is divided into eight municipalities or baladiya in Arabic: Doha, Al Rayyan, Al Wakra, Umm Slal, Al Dayyen, Al Sheehaniya, Al Khor, and Al Shemal. The vast majority of Qatar's population reside in urban areas, concentrated around the capital city of Doha. Because Qatar is geographically small, many government operations remain centralized in Doha and decentralization is limited to the provision of basic services by appointed government officials.

The authors recruited the purposive sample of eight key informants at all the municipalities, all of whom held the head of customer service department. Purposive samples prioritize qualitative findings from particular perspectives within the population. We contacted by phone and e-mail to

Figure 1. Organizational structure

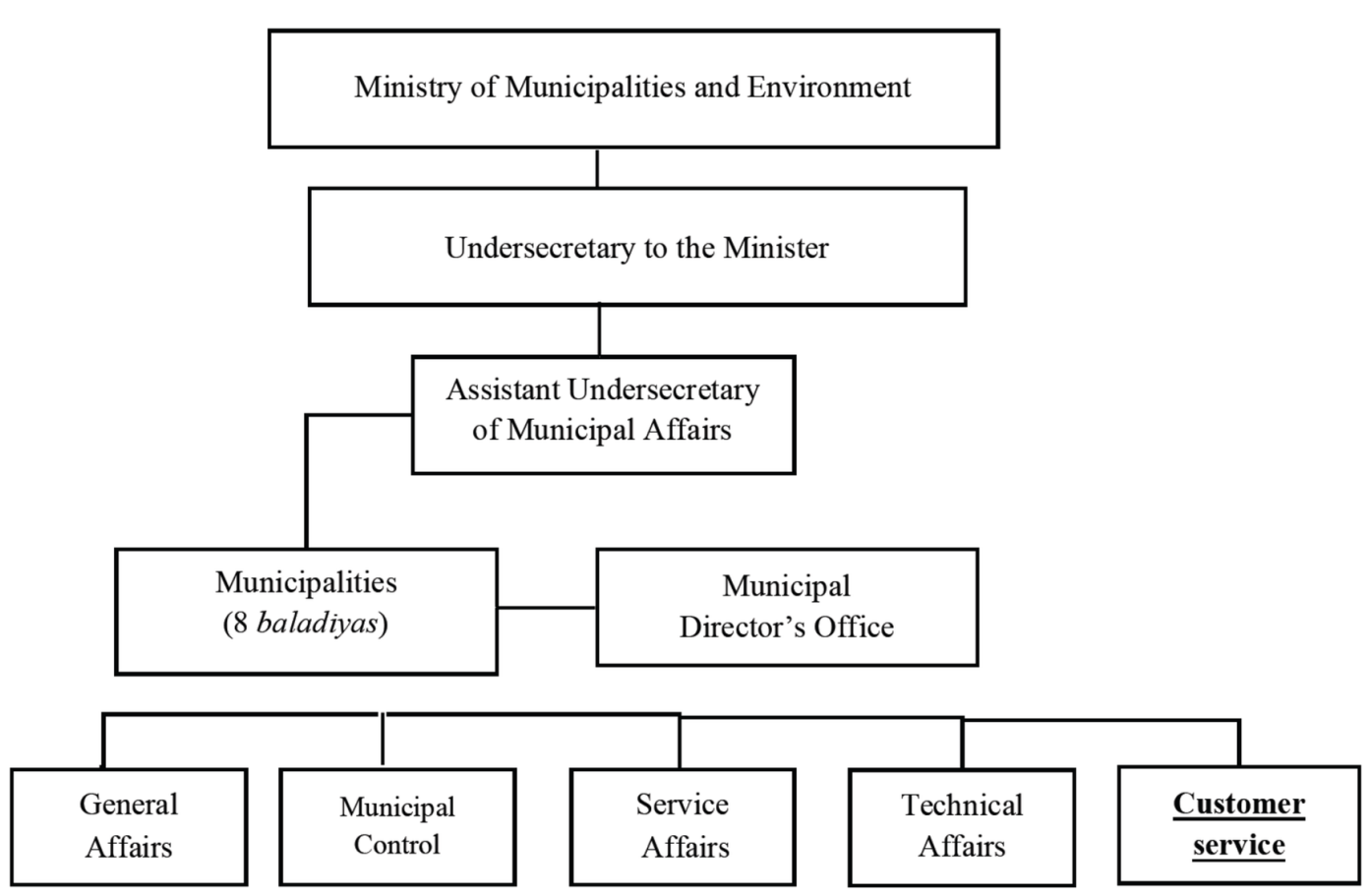


explain the purpose of the interviews and the potential questions that they might encounter during these interviews. When they agreed to participate, appointments for the interviews were made and these took place mostly at the participant's workplace inside at local government office building, often the same location as the municipal customer service center.

\section{Data Collection: Qualitative Interviews}

Interviews were conducted between November 2016 and February 2018. At all municipalities, researchers held one- to two-hour interviews with the director of customer service and whomever of his staff was invited to attend. The interviews were conducted in Arabic. Before starting the interviews, participants were told that their participation was voluntary (no compensation or incentives was provided). Interviews were audio recorded upon the consent of the participants. The participants were assured of confidentiality, which were included in the consent form.

A sequence of questions were prepared and derived from the reviewed literature and the researchers' background. Interviews consisted of a mixture of general questions about E-services, the citizen journey and the complaint life cycle when citizens interact with their local government. The Baladiya application was the first to receive large-scale promotion from the central government ministry, in the form of billboards throughout the country and other media. The e-services available both on the Ministry of Municipality and Environment's website and through the smartphone application are divided into four categories: (1) Municipal services: tree-pruning, pest control, drainage and sewage system maintenance, vehicle permits, rain water removal, trash services, vehicle towing, and more. (2) Environmental services: hazard materials protection, waste management, construction permits of various types. (3) Agricultural services: agriculture sector inspections and fees. (4) Public services: complaints and inquiries, engineering committees, tender and auctions committee.

\section{Data Analysis}

Interviews were transcribed (i.e., audio recordings were transcribed into written Arabic texts) and analyzed in Arabic using MAXQDA software for qualitative analysis. An inductive approach was used to allow research findings to emerge from the raw data. Each interview was analyzed by two bilingual members of the research team. After identifying relevant themes related to customer services and user contact, interview scripts were translated into English to facilitate publication. Although the translation procedure seems an apparently reasonable procedure, it involves a methodological limitation in terms of data interpretation. Yet, the quality of the translated texts was improved by checking their validity. The software enabled concentration on meaningful interpretations of the interview texts. The thematic analysis of the interview transcripts led to the main findings discussed below.

\section{DISCUSSION}

This section discusses the promises and problems associated with e-government systems from the perspective of municipal section-heads (also called directors of customer service) in Qatar. While each reported different experiences and issues unique to their locality, several similar themes emerged regarding their overall view of e-government as it currently applies to local service provision. Almost all praised the online coverage of e-government services and noted that it has made some aspects of services provision more efficient for customers and local bureaucrats alike. However, three categories of difficulties also emerged. The first surrounds the large quantity but poor quality of complaints, which complicates the customer service relationship. The second juxtaposes municipal civil servants who have a compelling service mandate with poorly informed and mildly engaged citizens. The third provides a possible reason for this contrast; e-government has opened many channels of communication, while the process of handling complaints remains opaque. The result is an e-government system that has succeeded in increasing service provision efficiency but has stopped short of is potential to promote participatory norms and transparent governance. 


\section{Broad Coverage and Increased User Access}

E-government allows users access all the services provided by the ministry. For example, interviewee explained:

The municipality's application and the ministry's website offers a lot of services like providing trash containers, insecticides for insects and rats, sewage [services] and tree cutting. You can apply and make an appointment via the municipality's website. Then they will call you. Once [the municipal worker] comes to do the service, you sign that you received it. You didn't need to go to the municipality.

As an official from a rural municipality pointed out, this process is believed to be easier for service users:

This program made it easier on the users and me as an employee. You don't need to do much, just open your mobile phone and register. The complaint will be sent directly. We will receive it, solve it and reply to you.

Regarding the potential of e-government to overcome the inconveniences of distant municipal offices for rural users, one official said:

[One customer] tells you "I am working in Doha so I come to ask for a service and the place is far for me." Then he learns about [the website] from us, and he says "Ok. I didn't have any idea about the website. You didn't announce it well." When he comes [to the municipality], he knows about [the website] and finds it easier than coming in person.

Here, the official also alludes to the fact the website is not well known among users. E-government has decreased the number of customers that municipal employees have to deal with face-to-face at the municipal office. In fact, one interviewee claimed that the application had greatly decreased visitors:

Now [when] you entered the reception area, it was almost empty with only one female attendant. Probably, last year you wouldn't have seen it empty or without a large number of clients...Everyone was coming to have paperwork reviewed and everyone wanted something.

Thus e-government is viewed as making service provision more efficient for users who are not obliged to visit local offices as well as local employees who now attend fewer customers on municipal premises.

Finally, some local service directors also indicated that the e-government system for user requests makes it easier for governments to respond to citizen needs:

[E-government] services made it much easier for us to restrict the complaints, fix them, know their types, and analyze them.

Here, the director notes that the metadata attached to complaints, such as the categories or types, have aided local officials in formulating a response to requests and complaints. Several other directors mentioned that the e-government system has decreased the response time for some urgent service problems. One said:

In the past if you wanted to complain about sewage, you'd wait until the next day to pick up the phone and make an appointment for a coming day, but now by using the application, you just get a 
message that your complaint was received while you're sitting at home. The complaint is electronically transferred to the specialized department and the next day morning the action is done.

This ability to communicate urgent matters with the local government outside of the working hours presents a clear advantage to traditional modes of service provision, which are dependent on face-to-face meetings.

\section{Large Quantity, Poor Quality Complaints}

However, increased user access to services has also problematized some aspects of the customermunicipality relationship. In related discussions customer service directors revealed that e-government access had increased the quantity of complaints while decreasing their overall quality. The director of one of the more populous urban municipalities noted the following:

Because of the electronic service complaints system, a new door has opened for us. According to the statistics, in the past, complaints in one month [were about] 40 or 30 or 50 . Now it's doubled to 120 or 110 because now it's easy...50 to 60 percent [of complaints] are malicious, unnecessary, or not our specialty. So since it becomes so easy anyone off the street can do it, more effort [is required of] us to call them and check the complaint. If a person sees water in the street he searches for the municipality who is not doing its job to complain. They use bad language which is offensive.

This respondent was not the only one to mention the poor quality of information that the municipality receives from customers via the e-government system, particularly the smart-phone application. In fact, almost all of the officials interviewed said that they now receive more complaints due to the e-government system, some of which are incomplete and all of which require municipal staff follow up of some sort.

In addition to water on the road, municipalities reported numerous petty complaints related to restaurants and food safety. As one interviewee explained:

At first, it was hard to go to the municipality to complain about a restaurant because you found hair in the sandwich for example. You may feel burdened to go [out] for such a thing. But now you can just send a message, which is much easier, so the process has increased significantly.

While the smart-phone application makes it easier for users to voice concerns, it makes it more difficult for local employees to screen complaints and respond as necessary. This difficulty is exacerbated by the fact that application users often register complaints with insufficient information. Sometimes a picture of suspicious food is sent to local officials without the restaurant name or the contact information of the user registering the complaint. Thus the high quantity and low quality of communication taking place through the e-government systems presents a challenge to local governments in terms of efficient service provision and signals a lack of awareness and participatory culture.

\section{Ready Services, Reluctant Users}

A second issue related to the current e-government system is the contrast between local governments who are striving to provide services in an efficient and timely manner and users who are partially engaged at best. Throughout the interviews, all of municipalities mentioned their response time as a way of demonstrating responsiveness to citizen complaints. On interviewee mentioned the improvement in the speed of service delivery:

Of course, [today] is 100\% different from the past. People used to complain and they had to come to the municipality for that. Now there is no need for coming in personally. The person submits a request for a service and if procedures are normal, it takes some days, but before it used to take 3 to 4 months. 
Others said that every complaint and request would receive an appropriate response within two or three days. Notably, this was true for both urban and rural municipalities, and for those dealing with large as well as small volumes of complaints.

This situation can be contrasted with the lack of enthusiasm from users. As can be seen from the restaurant complaint scenario discussed above, customers are not overly eager to work with the government to co-produce innovative solutions to local problems. In reality, e-government systems at present are not participatory in the full sense of the word. The users are limited to reporting dirty restaurants, zoning violations, and neighborhood disturbances. Their hands-off approach to governance is understandable when one remembers that in Qatar, no taxes are paid, none of the civil servants are elected, and all government services are financed by the country's natural resource wealth. There is a sense in which e-governance should not be expected to supersede the country's traditional economic and political structure.

However, the reluctance of users to fully participate in new digital systems could have less to do with rentier apathy and more to do with fact that these processes do not capture customer needs in terms of dialogue with the government. Almost all of the local officials we spoke to indicated that the appetite for connecting with the local government via traditional and personal channels remained strong, at least among some constituents. For example, the daily talk-radio show, "My Beloved Nation, Good Morning," which hosts conversations between members of government and callers who wish to air their complaints, continues to be popular with Qatari nationals. Local government officials recognized it as an important source of information about customer needs. In addition, many users still come in person or call municipal offices to explain their problem. Older and illiterate users were identified by the majority of respondents as preferring face-to-face interactions. Others go to the municipal office because they want to make sure their needs are promptly attended to, but as one participant explained, those who come in person should not expect expedited treatment compared to those who use the smart-phone application:

Some people prefer personal presence to oversee the procedures, but there is a sequence to the procedure. Whether or not the person filed a complaint electronically, in two days we must reply to him.

Finally, findings revealed that many potential users of e-government processes are simply illinformed. As previously mentioned, customer-service directors related examples of face-to-face conversations with users in which they introduced the smart-phone application or website to users who complained that they had never heard about it. Low user adoption rates cannot be explained by a lack of internet coverage. Qatar has a high level of internet penetration (estimated at 93\% in 2016) and Qatari nationals have a high internet usage, including $90 \%$ for males and $87 \%$ for females (Shockley et $a l$. 2018). This finding is consistent with other studies that have shown access to the internet is not the number one factor affecting e-government usage (Al-Adawi et al., 2005). Instead, low adoption rates call into question the success of government awareness campaigns to inform customers about the availability of e-government services and how to use them.

\section{New Channels, Opaque Process}

By and large, local government officials viewed the way in which e-government offers new opportunities for users to contact the government as synonymous with good governance. One official said the following:

We have big responsibilities... The citizen has to have choices for the same service either by presence, phone, or electronic means... We offer home visits for people in need. For example, an employee from customer service visits a sick person who is not able to talk and file a complaint. 
In this example, the list of possible avenues for service provision was even extended to include house visits to sick people who could not use other means. The respondents were careful to present themselves and their employees as civil servants who are ever-attentive to the needs of users. Yet their duty is clearly to respond to the issues raised by the users rather than design or revise the customer system itself, which is a centralized process originating with national-level officials. For example, when asked to suggest improvements to the system, one interviewee declined to comment saying that the question was ill-suited to his background and role.

Despite the centralization of the e-government system, which aims to make service provision consistent across municipalities, the increased number of services offered has led to a rather opaque user experience. The situation is complicated by the fact that other government entities have also implemented e-government programs and increased their offering of digital services recently. Actually, users often approach the incorrect government entity for their needs, and often municipal offices are on the receiving-end of complaints that should be directed elsewhere. The municipal official can either call the user to inform him of the correct entity to contact, or the official can reply within the online system to transfer the query. One official said the following:

The most [frequent] complaint we receive is, for example, about water in the streets because of a broken pipe. And this is not our job as a municipality. So, we tell them that it is [the utility agency's] job so he must go there, then I write in the system that [the issue] pertains to [the utility agency]. I must be sure to do that, because even if I close [the request], it will go back to the public relations office. Then they check if it really pertains to them or not, and if we contacted [the customer] or not. There are some people who keep an eye on our work.

This implies that local governments are kept accountable by a centralized public relations agency that manages cases in the e-government system and requires local officials to assist users in contacting the correct entity. On the other hand, users, who are largely unaware of the inner workings of the government, can be contacted by multiple government agencies at the same time about the same problem. The complex system for transferring complaints digitally between government entities is intended to provide faster solutions, but it consequently decreases the clarity of responsibility and transparency since customers often remain uncertain about the process.

Respondents also revealed that the vagaries of the municipal e-government system are typical of Qatar's centralized but internally disorganized bureaucracy. As one candidly stated:

The decisions that come from the [central] ministries are in need of coordination. For example, a decision came from the Ministry of Economy to implement some procedures, and it surprised me. I think we need to improve and adjust to reality. The higher managers that make decisions do not know what users need.

Thus, while helpful in creating access points for users, the e-government must work within the limitations of the existing bureaucratic norms, which at the moment, combine to make a labyrinthine customer experience. Problems do get fixed, but users are rarely sure how or by whom the results were achieved.

\section{CONCLUSION}

An e-government system promises increased efficiency, transparency, and participation. Qatar has taken steps toward modern and inclusive governance through implementing numerous e-government applications and websites that offer easy access to services. According to local officials, the e-government has increased access to services and therefore represents real progress toward efficiency 
in keeping with Qatar's E-government 2020 strategy. Yet the findings also reveal inconsistencies in management and implementation. Increased usage of the municipal application has lowered the bar for registering minor or incomplete complaints which drain local resources and divert time from more weighty matters. These superfluous complaints also signal that the level of citizen involvement with the local government and the co-production of the services could be improved. Many users with legitimate concerns are not aware of the e-government system, and others simply prefer to address concerns through the traditional channel such as in person or via well-known radio stations. While an e-government system can never fully replace face-to-face conversations for all users, governments should take measure to increase awareness of digital services.

In this process, the goal should not merely be to have more users registered on the application or the website, but to create a unified complaint process that will translate into a transparent user experience and increase the quality of the service delivery and government efficiency. At present, the e-government system falls short of its aim to enhance government openness because openness implies transparency of process and clarity of responsibility. The government is deploying efforts to increase services provision efficiency, but how it achieves this goal has not been made plain to the public. This lack of transparency in the complaint process helps account for disengaged users who passively take photos of suspicious restaurants and wait for the government to act but do not actively work with local entities to achieve better governance.

Finally, the roles and perspectives of the users are vital to success, and reform efforts must vigorously solicit their input. Here, an increased leadership commitment, and practical awareness campaigns are needed. However, the role of local officials is also essential to e-government implementation. In contrast to national-level actors who design e-government systems, local officials are on the frontline of service provision and are responsible for linking users with the government bureaucracy both locally and nationally. The reform process must consider their perspectives and experiences as well. Both users and local officials are critical components of the implementation process which will determine whether the country achieves its national goals for an efficient and open e-government system. 


\section{REFERENCES}

Al-Adawi, Z., Yousafzai, S., \& Pallister, J. (2005). Conceptual model of citizen adoption of e-government. Proceedings of the Second International Conference on Innovations in Information Technology IIT'05. Academic Press.

Al-Kubaisi, A. S. (2018). Enhancing the Adoption of E-Government Systems through Open Government and Open Government Data (OGD) Initiatives in Qatar. Journal of Information Engineering and Applications, 8(1).

Al-Shafi, S. (2008). Free wireless internet park services: An investigation of technology adoption in Qatar from a citizens' perspective. Journal of Cases on Information Technology, 10(3), 21-34. doi:10.4018/jcit.2008070103

Al-Shafi, S., \& Weerakkody, V. (2008). The use of wireless internet parks to facilitate adoption and diffusion of e-government services: An empirical study in Qatar. AMCIS 2008 Proceedings. Academic Press.

Al-Shafi, S., \& Weerakkody, V. (2009). Understanding citizens' behavioural intention in the adoption of e-government services in the state of Qatar. Proceedings of the ECIS (pp. 1618-1629). Academic Press.

Al-Shafi, S., \& Weerakkody, V. (2010). Factors affecting e-government adoption in the state of Qatar. Proceedings of the European and Mediteranean Conference on Information Systems, Abu Dhabi, UAE. Academic Press.

Al-Shafi, S., Weerakkody, V., and Janssen, M. (2009). Investigating the adoption of eGovernment services in Qatar using the UTAUT model. AMCIS 2009 Proceedings, 260. Academic Press.

Al-Yafi, K., Hindi, N. M., \& Osman, I. H. (2016). A User-Centric Evaluation of e-Government Services in the GCC Region: Case of State of Qatar. International Journal of Electronic Government Research, 12(4), 15-34. doi:10.4018/IJEGR.2016100102

Bertot, J. C., \& Grimes, J. M. (2010). Using ICTs to create a culture of transparency: E-government and social media as openness and anti-corruption tools for societies. Government Information Quarterly, 27(3), $264-271$. doi:10.1016/j.giq.2010.03.001

Chadwick, A., \& May, C. (2003). Interaction between States and Citizens in the Age of the Internet:"eGovernment" in the United States, Britain, and the European Union. Governance: An International Journal of Policy, Administration and Institutions, 16(2), 271-300. doi:10.1111/1468-0491.00216

Chatfield, A. T., \& Alhujran, O. (2007). E-government service delivery capabilities: An analysis of the Arab countries in Africa \& the Middle East. In E. El-Qawasmeh (Eds.), The 1st International Conference on Digital Communication \& Computer Applications (pp. 615-624). Amman, Jordan: Jordan University of Science and Technology.

Chatfield, A. T., \& Alhujran, O. (2009). A cross-country comparative analysis of e-government service delivery among Arab countries. Information Technology for Development, 15(3), 151-170. doi:10.1002/itdj.20124

De Bel-Air, F. (2014). Demography, Migration, and Labour Market in Qatar “Explanatory Note No. 8/2014.” Gulf Labour Market and Migration (GLMM), Programme of the Migration Policy Center (MPC) and the Gulf Research Center. GRC.

Ezz, I. (2003). Towards e-government adoption: some organizations challenges for the Egyptian government. Proceedings of the 2003 International Business Information Management Conference. Academic Press.

Foley, P., \& Alfonso, X. (2009). E-government and the transformation agenda. Public Administration, 87(2), 371-396. doi:10.1111/j.1467-9299.2008.01749.x

Ghaziri, H. (2003). Prerequisites for Building E-Government: The case of the Arab countries. Proceedings of the 2003 International Business Information Management Conference. Academic Press.

Kraemer, K., \& King, J. L. (2006). Information technology and administrative reform: Will e-government be different? International Journal of Electronic Government Research, 2(1), 1-20. doi:10.4018/jegr.2006010101

Liu, S. M., \& Yuan, Q. (2015). The evolution of information and communication technology in public administration. Public Administration and Development, 35(2), 140-151. doi:10.1002/pad.1717

Ministry of Municipality and Environment, Government of Qatar. (n.d.). Retrieved from http://www.mme.gov. qa/cui/view.dox? $\mathrm{id}=584 \&$ site $I D=2$ 
Norris, D. F., \& Reddick, C. G. (2013). Local e-government in the United States: Transformation or incremental change? Public Administration Review, 73(1), 165-175. doi:10.1111/j.1540-6210.2012.02647.x

Rabaai, A. A. (2015). An empirical investigation on the adoption of e-Government in developing countries: The case of Jordan. Computer and Information Science, 8(3), 83. doi:10.5539/cis.v8n3p83

Rodriguez Bolivar, M. P., Caba Perez, C., \& Lopez Hernandez, A. M. (2007). E-Government and public financial reporting: The case of Spanish regional governments. American Review of Public Administration, 37(2), 142-177. doi: $10.1177 / 0275074006293193$

Sahraoui, S. (2005). E-government in the Arabian Gulf: Government transformation vs. government automation. E-Government Workshop, 5, 13.

Salem, F. (2006). Exploring E-Government Barriers in the Arab States. Policy Briefs Series. Retrieved from https://ssrn.com/abstract=1498455

Shockley, B., Al-Lari, N., Elmaghraby, E., \& Al-Ansari, M. H. (2018). Social Media Usage and Women's Empowerment in Qatar: Evidence from a National Representative Survey. In Qatar Foundation Annual Research Conference Proceedings. Academic Press. doi:10.5339/qfarc.2018.SSAHPP1145

Weerakkody, V., El-Haddadeh, R., \& Al-Shafi, S. (2011). Exploring the complexities of e-government implementation and diffusion in a developing country: Some lessons from the State of Qatar. Journal of Enterprise Information Management, 24(2), 172-196. doi:10.1108/17410391111106293

Weerakkody, V., El-Haddadeh, R., Al-Sobhi, F., Shareef, M. A., \& Dwivedi, Y. K. (2013). Examining the influence of intermediaries in facilitating e-government adoption: An empirical investigation. International Journal of Information Management, 33(5), 716-725. doi:10.1016/j.ijinfomgt.2013.05.001

Zhou, H. (2001). Global perspectives on E-government [presentation]. Proceedings of the United Nations Third Caribbean Ministerial Consultation and High-Level Workshop in Jamaica (Vol. 11). Academic Press.

Nada Abdelkader Benmansour is Research Assistant Professor at the Social and Economic Survey Research Institute (SESRI) - Qatar University. She received her PhD in Economics from the University of Paris 1 La Sorbonne. Her research areas are Economics of Public Services, New Public Management, Public Services, Quality, Public Private Partnerships (PPP). Before joining SESRI, she was lecturer in economics and management in Tunisia.

NNoora Lari is a Research Assistant Professor and the Acting Manager of Policy Department at the Social \& Economic Survey Research Institute (SESRI) - Qatar University. She received her Ph.D. in Sociology and Social Policy in 2016 from the University of Durham. Her research areas are contemporary sociology, youth and organizations developments and the social changes in the Gulf region. In relation that, Lari is an active member at several committees within Qatar University such as - QU Institutional Review Board (IRB) committee.

Bethany Shockley $(P h D)$ is Assistant Professor of Political Science in the Department of International Studies at the American University of Sharjah, Sharjah, UAE. Previously she was a Research Associate at the Social and Economic Survey Research Institute (SESRI), Qatar University. Her PhD is in political science from Texas A\&M University. Her research focuses on comparative public opinion and political behavior, and gender and identity in the Arab Gulf. 